\title{
Organic matter removal via activated sludge immobilized gravel in fixed bed reactor
}

\author{
Banu Sizirici ${ }^{1, *}$, Ibrahim Yildiz $^{2}$ \\ ${ }^{1}$ Khalifa University of Science and Technology, Civil, Infrastructure and Environmental Engineering Department, Abu Dhabi, P.O Box: \\ 127788, United Arab Emirates \\ ${ }^{2}$ Khalifa University of Science and Technology, Chemistry Department, Abu Dhabi, P.O Box: 127788, United Arab Emirates
}

\begin{abstract}
In this study, the adsorption capability of the activated sludge immobilized gravel as a low-cost and efficient adsorbent to remove organic matter in terms of chemical oxygen demand (COD) from synthetic wastewater was investigated using fixed bed columns. The effects of parameters including column pack height and influent COD concentrations on removal efficiencies were assessed through breakthrough curves. It was found that the removal efficiency increased when fixed bed height was increased and influent COD concentration was decreased. The maximum COD removal rate of $36.35 \%$, was obtained for a medium-strength wastewater sample with $1166 \mathrm{mg} / \mathrm{L}$ of COD concentration when the bed height was $2 \mathrm{~cm}$, and the flow rate was $11 \mathrm{~mL} / \mathrm{min}$. Activated sludge immobilized gravel can be utilized as a low cost biofilter to remove organic material from wastewater.
\end{abstract}

\section{Introduction}

The concentration of organic pollutants is the main parameter to describe the strength of the wastewater. Industrial and municipal wastewater contain a variety of organic compounds. Illegal dumping and ineffectively treated wastewater effluents can cause pollution to the receiving bodies in the environment. Therefore, unconventional low-cost treatment systems are attracting more attention because of their ability to effectively remove organics from wastewater[1].

Gravel is one of the natural materials that has been underutilized even though it exhibited potentials to be a low-cost, effective adsorbent in wastewater treatment. Several studies have shown that gravel exhibited high adsorption capacities towards nitrogen, phosphorus, biochemical oxygen demand (BOD), chemical oxygen demand (COD), total organic carbon (TOC), metal ions, and some bacteria [2-6]. The biodegradation is suggested as a low-cost and efficient technique to degrade the organic pollutants from wastewater [5, 7-12]. Among different biologic treatment systems, biofilter/biorector systems utilizing immobilization of microorganism on different media were studied extensively to remove phenol, chlorophenol, dichlorophenol, quinoline, phthalic acid esters, nitrogen, heavy metals, and azo dye [13-19]. Experimental studies showed that immobilized microorganisms in a bioreactor showed higher removal rates when compared to conventional suspended systems. A tubular packed bed bioreactor with immobilized activated sludge culture showed $90 \%$ of COD removal from wastewater [20]. Another study reported formaldehyde degradation in a bioreactor with pumice stone as a support, and showed $97.1 \%$ of formaldehyde and $88 \%$ of COD removal efficiencies on average [21]. Surfactant-modified zeolites having a range of sizes from $0.25 \mathrm{~mm}$ to $0.5 \mathrm{~mm}$ removed phosphorus between $3.56 \%$ to $65 \%$ efficiencies when immobilized with orthophosphate accumulating bacteria [22].

A good carrier for the immobilization should be insoluble and stable in water, easily accessible, low-cost and non-toxic to microorganism [19]. In this respect, in this study gravel as a low-cost adsorbent was chosen as carrier for immobilization of activated sludge. Accordingly, activated sludge immobilized gravel (GAS) was evaluated to remove organic matter in terms of COD from wastewater in fixed bed reactor. COD is a measurement of the oxygen required to oxidize organic matter in water [23]. The effects of parameters including column pack height and influent COD concentration on the effluent COD concentration were investigated using breakthrough curves.

\section{Materials and Methods}

\subsection{Filter media preparation}

The gravel in the fixed bed columns were composed of particle with the diameters of $2.38-2.8 \mathrm{~mm}$. It was characterized with a variety of analytical and spectroscopic techniques including scanning electron microscope (SEM), energy-dispersive X-ray (EDX), XRay diffraction (XRD), and Brunauer-Emmett-Teller (BET) surface area analysis. The results of the

Corresponding author: banu.yildiz@ku.ac.ae 
characterization were published elsewhere [24, 25]. The immobilization of the activated sludge on gravel was verified with SEM using JSM-7610F. The gravel was coated with platinum by an auto fine coater, JEOL JEC$3000 \mathrm{FC}$, in 40 second and at $40 \mathrm{~Pa}$ for SEM images.

\subsection{Synthetic wastewater preparation}

An established protocol was adopted to prepare the synthetic wastewater samples [24-27]. All the measurements were run at $\mathrm{pH} 7$ adjusted by using $\mathrm{NaOH}$ or $\mathrm{HCl}$ solutions. The effect of wastewater concentration on the adsorption efficiency was analyzed by changing the strength of the wastewater. The initial synthetic wastewater solution was termed as strong $1 \mathrm{X}$ wastewater, and found to have $3575 \pm 131.52 \mathrm{mg} / \mathrm{L}$ of COD. $0.5 \mathrm{X}$ synthetic wastewater was found to contain $1166 \mathrm{mg} / \mathrm{L}$ of COD. All chemicals were analytical reagent grade and obtained from Fisher Scientific and Sigma Aldrich. Influent and effluent COD concentrations were determined using Hach LCK 314 COD vials which were digested in Hach DRB200 digital thermostat reactor and measured in Hach DR6000 UV-visible spectrophotometer. A Hach multi-meter HQD4D was used to measure the $\mathrm{pH}$.

\subsection{Immobilization of activated sludge culture on gravel and fixed bed operation}

An activated sludge sample as microbial immobilization culture was obtained from the second clarifier of a local wastewater treatment plant in Abu Dhabi/UAE. The activated sludge was transferred to a laboratory scale aeration tank and kept at $24{ }^{\circ} \mathrm{C}$ with dissolved oxygen (DO) amount of $7 \pm 1 \mathrm{mg} / \mathrm{L}$ and fed by synthetic feeding solution. The protocol for the preparation of synthetic feeding solution was adopted from a previous study [28]. Activate sludge culture containing $1063+150 \mathrm{mg} / \mathrm{L}$ mixed liquor suspended solids (MLSS) was recirculated by a peristaltic pump (Welch Model 3200) through the duplicates of columns having $8 \mathrm{~cm}$ height and $1.6 \mathrm{~cm}$ inner diameter at $11 \mathrm{ml} / \mathrm{min}$ flow rate for the immobilization on gravel as shown in Figure 1. The culture solution was replaced daily for 7 days for full immobilization. The immobilization of the microorganism was observed visually as well as with SEM. Activated sludge immobilized gravel was named as GAS. After 7 days, column media was covered with sludge, and the continuous column study was started. Synthetic wastewater solutions were stirred using a magnetic stirrer and pumped in upward direction in the columns by a peristaltic pump. The $\mathrm{pH}$ of the samples was adjusted to 7 to mimic the $\mathrm{pH}$ of the municipal wastewater. Effluent samples were collected at different times, then filtered using $0.45 \mu \mathrm{m}$ syringe filter, and analyzed with the UV-VIS spectrophotometer.

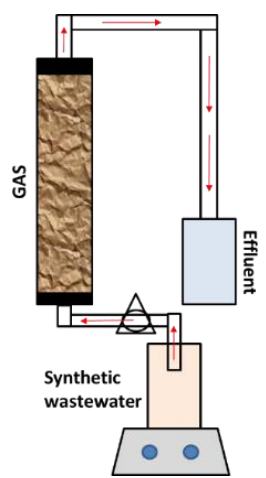

(b)

Fig 1. Column set up for activated sludge immobilized gravel (GAS)

Wastewater flow was terminated at time $\mathrm{t}$ when the concentration of a COD in the effluent was found to reach $98 \%$ of its initial concentration based on the formula $\mathrm{C}_{\mathrm{t}}=0.98 \times \mathrm{xC}_{\mathrm{o}}$ where $\mathrm{C}_{\mathrm{t}}$ is the COD concentration at time $t$, and $\mathrm{C}_{\mathrm{o}}$ is the initial COD concentration in the wastewater sample.

The total adsorbed organic materials, $\mathrm{q}_{\mathrm{total}}(\mathrm{mg})$, is equal to the area under the curve for the concentration of adsorbed organic, $\mathrm{C}_{\mathrm{ad}}\left(\mathrm{C}_{\mathrm{ad}}=\mathrm{C}_{0}-\mathrm{C}_{\mathrm{t}}\right)(\mathrm{mg} / \mathrm{L})$ over the time, $\mathrm{t}$ (min) using Eq. (1):

$$
q_{\text {total }(\mathrm{mg})}=\frac{Q . A}{100}=\frac{Q}{1000} \int_{0}^{t_{\text {total }}} C_{a d} d t
$$

where $\mathrm{Q}$ is the volumetric flow rate $(\mathrm{mL} / \mathrm{min})$. The dynamic adsorption capacity, $\mathrm{q}_{\mathrm{e}}(\mathrm{mg} / \mathrm{g})$, was calculated using Eq (2):

$$
q_{e}=\frac{q_{\text {total }}}{m}
$$

where $\mathrm{m}$ is the mass of adsorbent $(\mathrm{g})$. The removal efficiency of organic matter is the ratio of total adsorbed organic matter in the column to the total amount of organic matter found in the influent according to Eq. (3):

$$
\text { Efficiency }=\frac{q_{\text {total }}}{C_{o_{0} \frac{Q}{1000} t_{\text {total }}}} \times 100
$$

The column adsorption capacities were calculated based on the Thomas model according to Eq(4):

$$
\operatorname{Ln}\left(\frac{C_{0}}{C_{t}}-1\right)=k_{T h} q_{0} \frac{m}{Q}-k_{T h} C_{0} t
$$

where $\mathrm{k}_{\mathrm{th}}$ is the Thomas rate constant (L/mg.h), $\mathrm{q}_{0}$ is the Thomas column adsorption capacity $(\mathrm{mg} / \mathrm{g})$ and $\mathrm{t}$ is the filtration time (min). The linear graphs of $\ln \left[\left(C_{0} / C_{t}\right)-1\right]$ against $t$ were plotted to derive the values of $k_{\text {th }}$ which correspond to the slope and $q_{0}$ which corresponds to the intercepts.

\section{Results}

\subsection{SEM results}


Immobilization on gravel was verified using SEM imagining. The SEM image revealed roughness on the surface of the gravel before immobilization as shown in Figure 2a, and the efficient immobilization of the microorganisms on the gravel as shown in Figure $2 \mathrm{~b}$. Microorganisms colonized macro pores and crevices of the gravel and resulted as a biofilm.

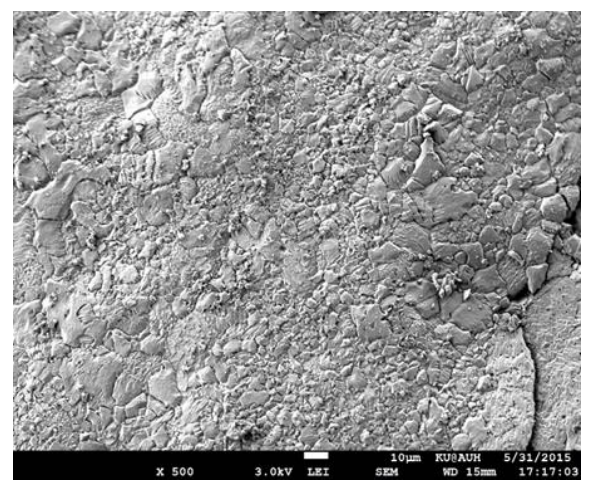

(a)

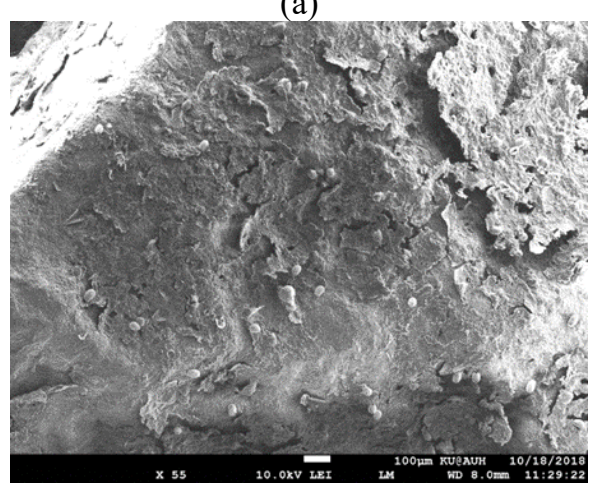

(b)

Fig 2. SEM images of (a) gravel at $500 \mathrm{X}$ (b) activated sludge immobilized gravel (GAS) at $500 \mathrm{X}$

\subsection{Fixed-bed column experiments}

The effect of the initial wastewater strength on the adsorption of the organic matter by GAS in the fixed bed column study was presented as $\mathrm{Ct} / \mathrm{Co}$ per day shown in Figure 3. Higher removal efficiency was obtained for $0.5 \mathrm{X}$ wastewater in columns with a bed height of $2 \mathrm{~cm}$. The average COD removal efficiency was $36.35 \%$ for $0.5 \mathrm{X}$ wastewater, whereas the COD removal efficiency decreased to $15.5 \%$ with $1 \mathrm{X}$ wastewater. This indicates that organic compounds saturate the binding sites immediately, and the performance deteriorates accordingly [27]. The total adsorbed COD was high for systems with high inlet COD concentration as shown in Table 1 . The adsorption process is driven mainly by the concentration gradient between adsorbent and solution. A high solute concentration in solution provides a strong stimulus for the efficient adsorption process, and this explains higher adsorption efficiencies towards samples with high COD concentrations [29].

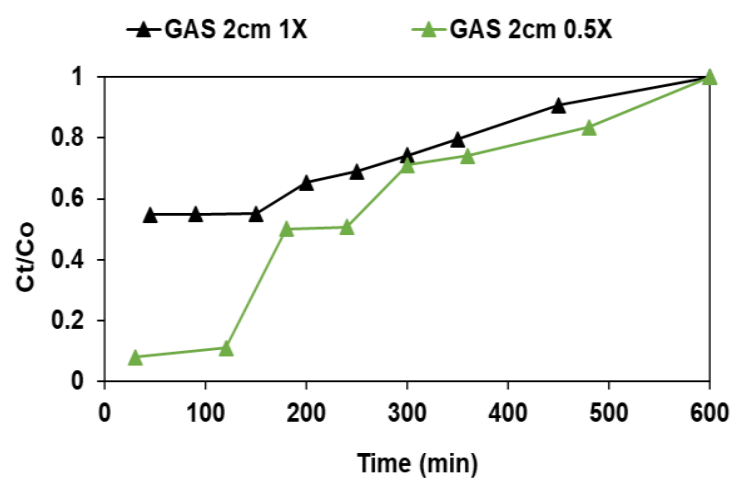

Fig 3. Breakthrough curves for $0.5 \mathrm{X}$ or $1 \mathrm{X}$ wastewater samples obtained for columns with $2 \mathrm{~cm}$ bed heights

Table 1. Exhaustion times, \% removals, and dynamic adsorption capacities

\begin{tabular}{|c|c|c|c|}
\hline Condition & $\mathbf{q}_{\mathrm{e}}(\mathbf{m g} / \mathbf{g})$ & $\mathbf{t}_{\mathrm{e}}(\mathbf{m i n})$ & \% Removal \\
\hline $\begin{array}{c}\mathbf{2} \mathbf{c m ~ 1 X} \\
\text { wastewater }\end{array}$ & 629.254 & 600 & 15.5 \\
\hline $\begin{array}{c}\mathbf{2} \mathbf{c m ~ 0 . 5 ~ X} \\
\text { wastewater }\end{array}$ & 588.126 & 600 & 36.35 \\
\hline $\begin{array}{c}\mathbf{4} \mathbf{~ c m ~ 1 X} \\
\text { wastewater }\end{array}$ & 1125.419 & 1050 & 20.66 \\
\hline
\end{tabular}

It was noted that the volume of treated wastewater as well as the amount of adsorbed organic matter increased as the bed height increased. The average COD removal efficiency was $20.66 \%$ for $1 \mathrm{X}$ wastewater in columns with $4 \mathrm{~cm}$ bed height and $15.5 \%$ for $1 \mathrm{X}$ wastewater in columns with $2 \mathrm{~cm}$ bed height as shown in Figure 4 . The higher the bed height was, the more the binding sites were available. The overall time to exhaust the column was found to be more for $4 \mathrm{~cm}$ bed height in GAS fixed bed columns. In this manner, columns with longer bed heights could operate in longer periods. In contrast, the exhaustion occurred faster with the shorter bed heights, therefore, the performance declined [30]. The amount of total adsorbed COD increased with the increasing bed height as shown in Table 2. Similar observations have been reported by other researchers [27, 31].

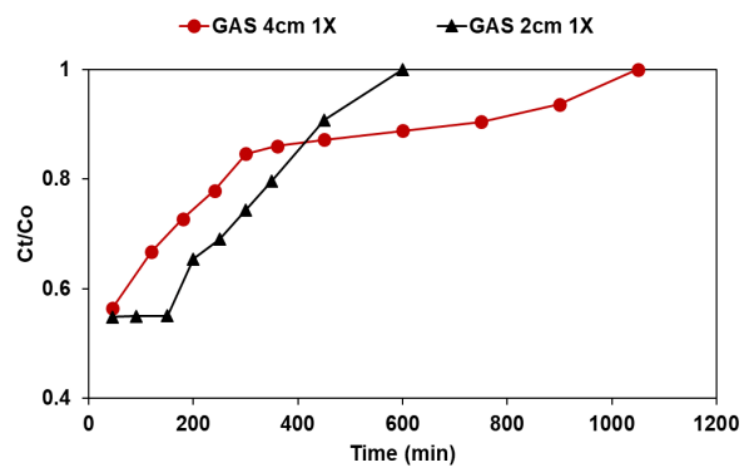

Fig 4. Breakthrough curves for $1 \mathrm{X}$ wastewater samples obtained for columns with $2 \mathrm{~cm}$ and $4 \mathrm{~cm}$ bed heights 
Some other studies reporting microorganism immobilized on different carriers showed higher COD removals than our study findings. For instance, the bacterium isolated from the wastewater was immobilized onto a new type of ceramic carrier by a vacuum method, and the resulting system removed more than $82 \%$ of the influent COD [32]. Another study revealed that, a pilot-scale zeolite medium biological aerated filter was able to remove $73.9 \%$ of COD for a sample with an initial concentration of $400 \mathrm{mg} / \mathrm{L}$ COD [33]. Lower COD removal rates in this study might stem from the choice of gravel as a carrier. According to another study, the number of immobilized cells decreased with an increase in the particle size of the carrier [34]. Another factor which might contribute to the lower removal efficiency of COD in this study could be use of high initial COD concentration which could decrease the removal percentage.

The breakthrough curves of COD for the wastewater samples using fixed bed columns were plotted, and the resulting data was described with the Thomas model. The values of $\mathrm{q}_{0}$ and $\mathrm{k}_{\mathrm{th}}$ indicating the performance of column were calculated. The GAS exhibited high-loading capacities for organic matters in fixed bed columns, and the uptake rate ranged from 785 $\mathrm{mg} / \mathrm{g}$ to $1293 \mathrm{mg} / \mathrm{g}$ of COD according to Table 2 . The correlation coefficients were between 0.91 to 0.99 indicating that Thomas model satisfactorily describes GAS adsorption capacities.

Table 2. Calculated values of $\mathrm{q}_{0}$ and $\mathrm{k}_{\text {th }}$ using Thomas model and corresponding $\mathrm{R}^{2}$ values

\begin{tabular}{|c|c|c|c|}
\hline Conditions & $\begin{array}{c}\mathbf{Q}_{\mathbf{0}} \\
(\mathbf{m g} / \mathbf{g})\end{array}$ & $\begin{array}{c}\mathbf{k}_{\text {th }} \\
(\mathbf{L} / \mathbf{m g . h})\end{array}$ & $\mathbf{R}^{\mathbf{2}}$ \\
\hline $\begin{array}{c}\mathbf{2} \text { cm 1X } \\
\text { wastewater }\end{array}$ & 785 & $7.6 \times 10^{-5}$ & 0.99 \\
\hline $\begin{array}{c}\mathbf{2} \text { cm 0.5 X } \\
\text { wastewater }\end{array}$ & 704.16 & 0.000625 & 0.91 \\
\hline $\begin{array}{c}\mathbf{4} \text { cm 1X } \\
\text { wastewater }\end{array}$ & 1292.53 & $4.55 \times 10^{-5}$ & 0.92 \\
\hline
\end{tabular}

The results shown in Table 3 clearly demonstrate the correlation between experimental results and Thomas model.

Table 3. Adsorption capacities of GAS obtained with experimental results and Thomas model

\begin{tabular}{|c|c|c|}
\hline Conditions & $\begin{array}{c}\mathbf{q}_{\mathbf{o}} \\
(\mathbf{m g} / \mathbf{g})\end{array}$ & $\mathbf{q}_{\mathbf{e}}(\mathbf{m g} / \mathbf{g})$ \\
\hline $\begin{array}{c}\mathbf{2} \text { cm 1X } \\
\text { wastewater }\end{array}$ & 785 & 588.126 \\
\hline $\begin{array}{c}\mathbf{2} \text { cm 0.5 X } \\
\text { wastewater }\end{array}$ & 704.16 & 629.254 \\
\hline $\begin{array}{c}\mathbf{4} \text { cm 1X } \\
\text { wastewater }\end{array}$ & 1292.53 & 1125.419 \\
\hline
\end{tabular}

\section{Conclusion}

The efficiency of activated sludge immobilized gravel in fixed bed columns was tested to treat high and medium strength wastewater samples in order to remove organic matter. It was deduced that lower COD inlet concentrations and higher bed heights improved the removal efficiencies of columns. The maximum COD removal rate of $36.35 \%$ was obtained for a mediumstrength wastewater sample $(0.5 \mathrm{X}$ wastewater $)$ with $1166 \mathrm{mg} / \mathrm{L}$ of initial COD concentration when the bed height was $2 \mathrm{~cm}$, and the flow rate was $11 \mathrm{~mL} / \mathrm{min}$. Activated sludge immobilized gravel as a low-cost medium can be utilized in bio-filters to remove organic content from wastewater efficiently.

\section{References}

1. Vidal, R. and J. Moraes, Removal of organic pollutants from wastewater using chitosan: a literature review. International journal of environmental science and technology, 2019. 16(3): p. 1741-1754.

2. Tchobanoglous, G., et al., Wastewater Engineering: Treatment and Resource Recovery. 2014: McGrawHill.

3. Battilani, A., et al., Decentralised water and wastewater treatment technologies to produce functional water for irrigation. Agricultural Water Management, 2010. 98(3): p. 385-402.

4. Ge, Y., et al., Functions of slags and gravels as substrates in large-scale demonstration constructed wetland systems for polluted river water treatment. Environmental Science and Pollution Research, 2015. 22(17): p. 12982-12991.

5. He, S., et al., Bioremediation of Wastewater by Iron Oxide-Biochar Nanocomposites Loaded with Photosynthetic Bacteria. Frontiers in Microbiology, 2017. 8(823).

6. Gulbaz, S., C.M. Kazezyilmaz-Alhan, and N.K. Copty, Evaluation of Heavy Metal Removal Capacity of Bioretention Systems. Water Air and Soil Pollution, 2015. 226(11).

7. Anjum, M., et al., Remediation of wastewater using various nano-materials. Arabian Journal of Chemistry, 2016.

8. Rattier, M., et al., Investigating the role of adsorption and biodegradation in the removal of organic micropollutants during biological activated carbon filtration of treated wastewater. Journal of Water Reuse and Desalination, 2012. 2(3): p. 127139.

9. Oh, S.-Y., et al., Microbial reduction of nitrate in the presence of zero-valent iron and biochar. Bioresource Technology, 2016. 200: p. 891-896.

10. Gandhimathi, R., et al., Use of combined coagulation-adsorption process as pretreatment of landfill leachate. Iranian journal of environmental health science \& engineering, 2013. 10(1): p. 24.

11. Zheng, C., et al., Treatment technologies for organic wastewater, in Water Treatment. 2013, Intech.

12. Agarwal, B., R.K. Vedula, and C. Balomajumder, Comparative studies on simultaneous adsorption and biodegradation, adsorption and biodegradation for treatment of wastewater containing cyanide and 
phenol. International Journal of Agriculture, Environment and Biotechnology, 2014. 7(3): p. 595.

13. Jianlong, W., et al., Immobilization of microorganisms using carrageenan gels coated with chitosan and application to biodegradation of 4 chlorophenol. 1997.

14. Jianlong, W. and Q. Yi, Microbial degradation of 4chlorophenol by microorganisms entrapped in carrageenan-chitosan gels. Chemosphere, 1999. 38(13): p. 3109-3117.

15. Jianlong, W., et al., Biodegradation of quinoline by gel immobilized Burkholderia sp. Chemosphere, 2001. 44(5): p. 1041-1046.

16. Zhang, Y., et al., High-carbohydrate wastewater treatment by IAL-CHS with immobilized Candida tropicalis. Process Biochemistry, 2005. 40(2): p. 857-863.

17. Zhang, L.-S., W.-z. Wu, and J.-1. Wang, Immobilization of activated sludge using improved polyvinyl alcohol (PVA) gel. Journal of environmental sciences, 2007. 19(11): p. 1293-1297.

18. Gönen, F. and Z. Aksu, $A$ comparative adsorption/biosorption of phenol to granular activated carbon and immobilized activated sludge in a continuous packed bed reactor. Chemical Engineering Communications, 2003. 190(5-8): p. 763-778.

19. Dzionek, A., D. Wojcieszyńska, and U. Guzik, Natural carriers in bioremediation: A review. Electronic Journal of Biotechnology, 2016. 19(5): p. 28-36.

20. Dizge, N., B. Tansel, and B. Sizirici, Process intensification with a hybrid system: A tubular packed bed bioreactor with immobilized activated sludge culture coupled with membrane filtration. Chemical Engineering and Processing: Process Intensification, 2011. 50(8): p. 766-772.

21. Ebrahimi, S. and M. Borghei, Formaldehyde biodegradation using an immobilized bed aerobic bioreactor with pumice stone as a support. Scientia Iranica, 2011. 18(6): p. 1372-1376.

22. Hrenovic, J., et al., Interaction of surfactantmodified zeolites and phosphate accumulating bacteria. Journal of hazardous materials, 2008. 156(1-3): p. 576-582.

23. Davis, M.L. and D.A. Cornwell, Introduction to environmental engineering. 2008: McGraw-Hill Companies.

24. Sizirici, B. and I. Yildiz, Adsorption capacity of iron oxide-coated gravel for landfill leachate: simultaneous study. International Journal of
Environmental Science and Technology, 2017. 14(5): p. 1027-1036.

25. Sizirici, B. and I. Yildiz, Simultaneous adsorption of divalent and trivalent metal cations by iron oxidecoated gravel. International Journal of Environmental Science and Technology, 2018: p. 110.

26. Sizirici, B., et al., Adsorptive removal capacity of gravel for metal cations in the absence/presence of competitive adsorption. Environmental Science and Pollution Research, 2018. 25(8): p. 7530-7540.

27. Sizirici, B. and I. Yildiz, Removal of Organics and Metals in Fixed Bed using Gravel and Iron Oxide Coated Gravel. Results in Engineering, 2020: p. 100093.

28. Dizge, N., B. Tansel, and B. Sizirici, Process intensification with a hybrid system: A tubular packed bed bioreactor with immobilized activated sludge culture coupled with membrane filtration. Chemical Engineering and Processing, 2011. 50(8): p. 766-772.

29. Aksu, Z. and F. Gönen, Biosorption of phenol by immobilized activated sludge in a continuous packed bed: prediction of breakthrough curves. Process biochemistry, 2004. 39(5): p. 599-613.

30. Lim, A.P. and A.Z. Aris, Continuous fixed-bed column study and adsorption modeling: Removal of cadmium (II) and lead (II) ions in aqueous solution by dead calcareous skeletons. Biochemical Engineering Journal, 2014. 87: p. 50-61.

31. Chowdhury, Z., et al., Breakthrough curve analysis for column dynamics sorption of Mn (II) ions from wastewater by using Mangostana garcinia peelbased granular-activated carbon. Journal of chemistry, 2012. 2013.

32. Kariminiaae-Hamedaani, H.-R., K. Kanda, and F. Kato, Wastewater treatment with bacteria immobilized onto a ceramic carrier in an aerated system. Journal of bioscience and bioengineering, 2003. 95(2): p. 128-132.

33. Tian, W.-h., X.-h. Wen, and Y. Qian, Using a zeolite medium biofilter to remove organic pollutant and ammonia simultaneously. Journal of Environmental Sciences, 2004. 16(1): p. 90-93.

34. Hrenovic, J., T. Ivankovic, and D. Tibljas, The effect of mineral carrier composition on phosphateaccumulating bacteria immobilization. Journal of Hazardous Materials, 2009. 166(2-3): p. 1377-1382. 